\title{
Suelo intraurbano vacante para vivienda en la ciudad de Tlaxcala, México. Una aproximación espacial
}

\section{Vacant Intraurban Land for Housing in the City of Tlaxcala, Mexico. A Spacial Approach}

\author{
Perla lleana Hernández López* (10) https://orcid.org/0000-0003-3431-8781 \\ Ramos Montalvo Vargas * (1) https://orcid.org/0000-0002-2385-5437
}

\section{Resumen}

El objetivo del estudio es identificar el suelo intraurbano vacante en la ciudad de Tlaxcala. La metodología se basó en técnicas de análisis espacial, uso de imágenes de satélite y sistemas de información geográfica. Se encontró en la región construida que la mayoría de los vacíos urbanos (63\%) están abandonados. Es en el centro de la ciudad capital donde hay un mayor número de ellos: 97 de 213 identificados, que representan $45.54 \%$. Sin embargo, dicho centro sólo representa $10 \%$ del área total de la ciudad. En cambio, la colonia Tepehitec, ubicada en la periferia, tiene 12 vacíos urbanos, que representan $40 \%$ del área de dicha colonia. Se concluye que la relación entre cantidad de vacíos urbanos y superficie disponible es inversa a medida que se incrementan las distancias desde el centro de la ciudad hacia su periferia: mientras el centro gana en cantidad, la periferia lo hace en superficie disponible. Queda pendiente la tarea de analizar la pertinencia de promover la densificación de vivienda en estos espacios para sentar las bases de un modelo de ciudad compacta.

Palabras clave: suelo intraurbano vacante; vivienda; espacio habitacional; Tlaxcala.

\begin{abstract}
The objective of the study is to identify the vacant intra-urban land (VIUL) in the city of Tlaxcala. The methodology was based on spatial analysis techniques and on the use of satellite images and Geographic Information Systems (GIS). In the built region it was found that most of the urban voids (63\%) are abandoned. The greater number of them are found in the center of the capital city: 97 of 213 were identified, which represent $45.54 \%$; however, the center of the capital city is only I0\% of the total city area. On the other hand, the Tepehitec neighborhood, located on the periphery, has I2 voids and concentrates $40 \%$ of that neighborhood area. It is concluded that the quantity-surface relationship is inverse in the center inasmuch as distances increase from the center of the city to the periphery: while the center gains in quantity, the periphery does it in available surface. It remains the task to analyze the suitability of promoting housing densification in these spaces to lay the foundations for a compact city model. Keywords: vacant intra-urban land; housing; living space; Tlaxcala.
\end{abstract}

Cómo citar: Hernández López, P. I., y Montalvo Vargas, R. (2020). Suelo intraurbano vacante para vivienda en la ciudad de Tlaxcala, México. Una aproximación espacial. región y sociedad, 32, e I279. doi: I0.22198/rys2020/32/I279

*Autora para correspondencia. Universidad Politécnica de Tlaxcala, Departamento de Investigación y Desarrollo Tecnológico. Ave. Universidad Politécnica Núm.1, San Pedro Xalcaltzinco, C. P. 90180. Tepeyanco, Tlaxcala, México. Correo electrónico: perla.hl.03@gmail.com

** Universidad Autónoma de Tlaxcala, Facultad de Ciencias para el Desarrollo Humano. Carretera Tlaxcala-Puebla km. 1.5, C.P.90070. Tlaxcala, Tlaxcala, México.Correo electrónico: rmontalvovargas@gmail.com

Recibido: 18 de diciembre de 2019

Aceptado: 30 de septiembre de 2020

Liberado: 5 de noviembre de 2020

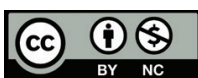

Esta obra está protegida bajo una Licencia

Creative Commons Atribución-No Comercial 4.0 Internacional. 


\section{Introducción}

El presente artículo responde a la preocupación por la creciente expansión de las ciudades mexicanas hacia su periferia sin planificación urbana, lo cual fomenta la proliferación de espacios residuales que crean una ciudad dispersa. $\mathrm{El}$ propósito del trabajo es identificar espacios intermedios denominados espacios vacantes intraurbanos, también conocidos como vacíos urbanos, con el objetivo de caracterizar su distribución espacial y analizar la pertinencia de su reutilización para una posible densificación de la ciudad y pensar, de manera alternativa, en la transición a un modelo de ciudad compacta. Los espacios vacantes son áreas residuales que han perdido su funcionalidad y se encuentran exentos de la dinámica urbana. Esta investigación se ocupa del suelo intraurbano vacante (SIV) de la ciudad de Tlaxcala, bajo el supuesto de que es posible su reutilización para densificar el entorno urbano y al mismo tiempo mitigar y controlar la expansión física de la ciudad.

La investigación parte de la regionalización a partir del uso de herramientas que analizan datos con componentes espaciales, usando como base los perímetros de contención urbana (PCU1-PCU2-PCU3), ya definidos en México por la Comisión Nacional de Vivienda (CONAVI), mediante una metodología aplicada en 2014 y actualizada en 2017, a partir de áreas de influencia de los centros de población con más de 15000 habitantes. De los tres perímetros, el trabajo se concentra en el perímetro interno, que corresponde al primer radio de intervención institucional.

La metodología empleada permitió localizar los espacios vacantes a partir del uso de teledetección espacial, que derivó en una cartografía a diferentes escalas, con la finalidad de interpretar su distribución en la ciudad, la cual se validó en campo a partir de recorridos derivados de la fotointerpretación de recursos ráster georreferenciados.

Los resultados muestran que estos espacios vacantes se localizan en toda el área de la ciudad, desde el centro hasta la periferia y son elementos repetitivos que se encuentran en cualquier segmento urbano. Sin embargo, el patrón de distribución tiene un comportamiento inverso en cantidad y superficie disponible a medida que se incrementan las distancias desde el centro de la ciudad hacia su periferia. Lo anterior permite sugerir que una ciudad necesita revitalizarse por medio de los espacios vacantes para transitar a un modelo de ciudad alternativo y que, para su intervención, se debe analizar e interpretar su potencial, donde los lugares identificados se conviertan en elementos capaces de fomentar la densificación como parte del proceso de contención urbana. Pero lo que ha ocurrido es lo contrario: los desplazamientos parciales o ampliados de actividades económicas, de ocio o administrativas se dirigen a otros subcentros de la ciudad, distantes del centro antiguo u original, lo cual ha reducido mucho la demanda del uso del núcleo que dio origen a la ciudad (Álvarez de la Torre, 2017). Este proceso de desuso ocasiona pérdida económica en el centro en términos de uso habitacional y por lo tanto un abandono del lugar por parte de la población residente, tal como viene ocurriendo en la ciudad de Tlaxcala. 
Por lo anterior, Tlaxcala se aproxima a un modelo alternativo de ciudad que se sitúa en la categoría de ciudades intermedias, que tienen rangos de población que van desde 50 mil hasta un millón de habitantes. Muchas de ellas están enclavadas todavía en zonas rurales en franco proceso de urbanización acelerada y, de no diseñarse estrategias efectivas de planeación, se convertirán en lugares incontrolables.

Se asume el tamaño de Tlaxcala como criterio de espacios ideales para la planificación territorial. Precedo y Míguez (2014) afirman que las ciudades medias pueden ser abordadas desde los atributos dimensionales y funcionales, por las ventajas comparativas que ofrecen en cuanto a la calidad de vida y a las oportunidades que representan para implementar políticas de estrategias de desarrollo. Tlaxcala por su estructura, aunque compleja, no impide tomar medidas para controlar la expansión. Por el contrario, se puede usar el espacio intraurbano disponible para densificar las islas desocupadas con vivienda suficiente ante la demanda de ésta, consecuencia del dinamismo económico en una ciudad intermedia como Tlaxcala.

Los vacíos urbanos protagonizan un papel relevante en la estructuración de la ciudad y abren posibilidades para su tramado desde nuevas perspectivas. El desafío es densificar la ciudad de manera articulada, sin perder su estilo tradicional e integrar estos vacíos como elementos configuradores del suelo intraurbano para que faciliten la transición al modelo de ciudad compacta.

\section{Un acercamiento conceptual}

El suelo intraurbano vacante (SIV) tiene una diversidad de acepciones: tierras vacantes, vacíos urbanos, espacios remanentes, lotes baldíos, vacíos en desuso, espacio subutilizado, suelo baldío, terrain vague, áreas abandonadas, tierra vacante latente, terrenos intersticiales, corazones de manzana, espacios de ausencia urbana, lugares de nostalgia, espacios sin identidad y lugares con caducidad o deterioro. Estas denominaciones convergen en esta investigación para entender el SIV como un espacio urbano en desuso sin presencia de construcción.

En Estados Unidos, desde 1986, se ha analizado la situación de la tierra vacante. Whitaker y Fitzpatrick (2013) hicieron un análisis empírico para estimar, a partir del modelo de precios hedónicos, el impacto que generan sobre la propiedad los impuestos, la delincuencia y la ejecución hipotecaria. Un par de años antes, durante la 110th American Congressional Assembly (2011, pp. 11-12), se señaló que en algunas zonas la tierra vacante se debía a la especulación. En esos casos las estrategias fueron las siguientes: a) tener el control de la tierra a través del gobierno; b) crear un gestor de incentivación de las propiedades; c) promover el uso alternativo de las tierras; y d) promover la relocalización de asentamientos irregulares ubicados en zonas de alto riesgo o con suelo de mala calidad.

Las labores en la materia continuaron con Mallach y Brachman (2013, pp. 27-29), al proponer la reconstrucción del núcleo (centro de la ciudad). Se expande el beneficio al resto de la ciudad, ya que es común que en el centro se 
encuentren diversas oficinas a las cuales acuden personas de distintas partes de la ciudad, además de que todavía hay residentes que requieren más comercios y servicios. Con esa intención, se busca aprovechar el espacio intraurbano vacante. Los autores también sugieren la reutilización de áreas abandonadas, porque existen personas que todavía las habitan. Sin embargo, se han convertido en pulmones verdes para otras zonas de la ciudad, por lo que invertir con infraestructura permitiría aportar beneficios futuros para la implementación de actividades en favor de la comunidad.

Nassauer y Raskin (2014, p. 246) partieron de dos preguntas fundamentales: ¿cómo pueden afectar las tierras vacantes y abandonadas el legado del pasado desde el punto de vista de los efectos sociales y medioambientales?; y ¿qué aspectos del bienestar humano y de la función medioambiental deben ser considerados cuando se gestionan las tierras urbanas vacantes?

En respuesta a estas interrogantes, y en desacuerdo con la propuesta de autores que afirman que el uso temporal de terrenos baldíos urbanos no es una panacea para crear ciudades resilientes y sostenibles desde el punto de vista social y ecológico; autores como Bishop y Williams (2012) afirman que la historia de las ciudades está llena de ejemplos de ciudades poderosas que terminan siendo temporales. Por eso el término "temporal" lo emplean como una solución vanguardista creativa de la planificación urbana que permite explorar mecanismos que sirven como elementos integradores a través de la dotación de nueva infraestructura, ante la evidente pobreza urbana que caracteriza muchas ciudades del mundo y que a menudo se define por ubicarse en un entorno físico temporal y en un estado de incertidumbre extrema y desafiante.

Para Pearsall, Lucas y Lenhardt (2014, p. 163), debe buscarse el equilibrio para armonizar tres objetivos en la ciudad que compiten entre sí y que están representados por tres tipos de espacios: verdes, comerciales y habitacionales. Mientras que autores como Foo, Martin, Wool y Polsky (2014) apoyan la idea de aprovechar los vacíos urbanos, pues afirman que las fuerzas económicas de tipo político y la intervención vecinal son factores fundamentales que impulsan la gobernanza de la tierra vacante en los barrios. Explican la importancia de éstos y de los espacios baldíos existentes en ellos y, después de su análisis, afirman que los lotes baldíos adquieren funciones y valores de acuerdo con sus condiciones físicas locales, los contextos sociales y económicos, además de que los jardines de la comunidad (que en muchos casos se convierten en lotes baldíos) refuerzan la vida comunitaria (pp. 156-157).

Foster (2014) utilizó el concepto terrain vague para referirse a paisajes que no están regulados y que se apartan del ámbito de los principales procesos urbanos; es decir, que no están integrados a la ciudad, por lo que son espacios vacíos abandonados con un potencial edificable (aprovechable) dentro de la ciudad. Quienes más enfatizan en la necesidad de reutilización de áreas abandonadas son Mallach y Brachman (2013), al afirmar que la participación social puede mejorar el uso y el significado de los terrenos baldíos.

Por su parte, Kremer, Hamstead y Mcphearson (2013) pudieron estimar, pese a no existir un estudio continuo sobre la situación que guardan los terrenos baldíos, que hacia 1970 algunos datos estadísticos en Nueva York apuntaban a 
que $90 \%$ de los lotes baldíos se consideraban aptos para el desarrollo urbano, es decir, para el aprovechamiento de la ciudad. Los autores precisan que "un primer paso hacia el desarrollo apropiado de terrenos baldíos para la infraestructura verde urbana es la creación de un mecanismo para identificar y clasificar las características sociales y ecológicas de terrenos baldíos en la escala de la ciudad" (p. 230).

Otro aporte sugerente es el de Clichevsky (2002, p. 48), quien afirmó que en América Latina hay un interés casi nulo por el tema de la tierra vacante. Los vacíos urbanos primero se explicaban como producto de la no ocupación de predios de sectores bajos y medios. En los últimos años eran resultado de los clubes de campo y barrios cerrados. Además, consideró los espacios baldíos de la ciudad como resultado de "múltiples y complejas acciones de los diferentes agentes públicos y privados, con distintos intereses”. Por lo tanto, no sólo está presente el componente económico; también están los componentes cultural, medioambiental y de seguridad, aparte de que el funcionamiento del mercado de tierras con escasas regulaciones es lo que mejor explica su comportamiento.

El acelerado crecimiento de las ciudades latinoamericanas está influido por el neoliberalismo vigente y, aunque esta macrorregión es un mosaico territorial con particularidades propias de sus países, el peso del capitalismo ha impuesto a lo largo de la historia los ritmos y las formas de estructuración de ciudades con especial énfasis en el mercado informal del suelo y la vivienda (Pradilla, 2014).

La desigualdad económica, social, ambiental y cultural impacta de modo diferente en los espacios urbanos, lo cual provoca la configuración de regiones con especificidades unas benéficas y otras catastróficas (ricas y pobres). El peso de alguna de esas variables en la sociedad capitalista actual y para cada país en América Latina en particular refleja la resistencia a la vigencia del sistema, que tiene como resultado expresiones territoriales compuestas por la hegemonía monopólica, grupos de control político y narcotráfico, pero también invisibilización de sectores sociales que forman parte del entramado urbano.

El eje de acumulación de capital se ve reflejado en el proceso de urbanización, donde las ciudades tienen, por un lado, sus espectaculares zonas exclusivas de concentración económica (comercial, servicios y vivienda) y, por otro lado, zonas de miseria con segregación espacial para el resto de la ciudad en interacción y mutua convivencia. Los resultados se traducen en diferenciales de renta del suelo con zonas privatizadas en favor del gran capital y la irregularidad o nula propiedad para sectores sociales desposeídos o de bajos recursos. Así mismo la fusión del capital financiero e inmobiliario se hace evidente, lo que provoca segregación socio-territorial (Pradilla, 2014). No obstante, en términos socioculturales, la clase relegada es la que se siente más identificada con la ciudad y la que más se apropia de ella.

Esa desigualdad provoca un cambio en las direcciones que toma la morfología de la ciudad, que es forzada por el poder del capital inmobiliario que tiene la base financiera para influir en la estructura urbana de las grandes metrópolis y con más facilidad en las ciudades intermedias, haciendo a un lado incluso las políticas y la planificación urbana. 
Otro aporte a escala latinoamericana lo expresa Araujo (2004), quien concluye que el suelo vacante puede contribuir de diversas formas: a la regulación del mercado inmobiliario, a facilitar el acceso de tierra a familias de bajos ingresos, al control del uso del suelo, a definir la expansión urbana, a concentrar o dispersar las inversiones públicas y privadas y, en general, a planificar, ordenar y procurar acciones de gestión territorial de la ciudad. Con esos principios, es que aparece la noción de función social de la propiedad como fundamento de toda acción pública de administración, planificación, ordenación y gestión territorial, así como también las distintas formas de cooperación y participación que favorecen el mejoramiento urbano (Cavalieri, Gerscovich y Wainstein-Krasuk, 2010, p. 4).

A pesar de los esfuerzos realizados por los diversos autores, queda una pregunta fundamental que orienta el presente trabajo: ¿cuál es la cantidad de tierra vacante existente en una ciudad?, es decir, aquella que está inutilizada como terreno baldío o que presenta desuso o desaprovechamiento a pesar de no estar baldía. A este respecto, Frediani (2014, p. 3) deja en claro que este suelo vacante intraurbano es estratégico para el control del crecimiento urbano y expresa que "la referencia tanto a la subutilización como a la falta de uso de terrenos y edificios abandonados de propiedad pública y/o privada" es fundamental para la contención de la ciudad.

En México, Fausto y Rábago (2001) definen el vacío urbano como espacio remanente a la dinámica urbana. Son aquellos terrenos urbanos que permanecen subutilizados, próximos a infraestructuras ya instaladas, y que no desarrollan su potencial, contrariando el principio de función social de la propiedad. No obstante, los autores incluyen espacios desocupados, construidos, con bajo potencial de aprovechamiento. En esta misma idea, Araujo (2004) los define como aquellos tramos de suelo urbano sin uso efectivo o que no alcanzan su mejor potencial de utilización. En el mismo sentido, Mignaqui y Arias (2008) consideran que es aquella tierra privada no utilizada que se encuentra subdividida en parcelas denominadas urbanas según la legislación vigente dentro del perímetro de una aglomeración, así como la tierra de propiedad fiscal que ha sido desafectada en sus anteriores usos.

Para Fausto (2005), los espacios vacantes son aquellos espacios construidos o utilizables -terrenos, edificaciones, grandes conjuntos o zonas- que se localizan al interior de áreas urbanizadas y que se encuentran desocupados, aun cuando su uso parezca inferior a su potencial de aprovechamiento urbano. En la misma tesitura, Godoy (2007) considera que son lotes insertos en el tejido urbano y que se encuentran en estado inutilizado.

En definitiva, es preciso reflexionar sobre el suelo intraurbano vacante desde el punto de vista físico, es decir, como espacio. Araque (2011, p. 2) lo describe como espacios de ausencia, nostalgia, no-identidad, caducidad y deterioro. No son sólo espacios libres de edificaciones, sino que además están inactivos en la trama urbana: representan estructuras ausentes de actividad e identidad. Esa concepción implica un espacio de identidad nula o indefinida, no reconocido por el colectivo, inmerso en la trama urbana y de grandes posibilidades de intervención para suturar partes inconexas de la ciudad. Con este punto de 
partida, el siguiente paso, difícil en términos metodológicos, es identificar esos vacíos con la finalidad de conocer sus características y su uso potencial en favor de la ciudad.

\section{Metodología}

En el año 2015, la Comisión Nacional de Vivienda (CONAVI) en México crea los perímetros de contención urbana (PCU) y los actualiza en 2017. Son tres y obedecen a distintos criterios: el PCU1 es un perímetro intraurbano con acceso a empleo, el PCU2 es una zona de consolidación urbana y el PCU3 representa una franja periférica de crecimiento (CONAVI, 2017). A partir de esta delimitación institucional que se aplica a todas aquellas ciudades del sistema urbano nacional (SUN) con más de 15000 habitantes, se estructura la metodología del presente trabajo.

Para alcanzar el objetivo del estudio, los datos se obtuvieron en dos etapas: primero se realizó un inventario de suelo intraurbano vacante dentro de los PCU con cobertura en la Ciudad de Tlaxcala. Se usaron la teledetección o percepción remota, que consiste en el manejo de imágenes de satélite de alta resolución espacial tipo Quickbird de la empresa Digital Globe, así como mosaicos disponibles en Google Earth Pro, a partir de los cuales se generaron archivos keyhole markup zip (KMZ) resultado de la digitalización manual, auxiliados con técnicas de fotointerpretación y fotoidentificación del espacio urbano vacante. En seguida, mediante el uso del software Global Mapper, se convirtieron los archivos de cada espacio digitalizado de tipo $\mathrm{KMZ}$ a formato de archivo shapefile. Para finalizar este proceso, a partir del manejo del software de sistemas de información geográfica (SIG), se emplearon algunas técnicas de análisis espacial, como áreas de influencia y geoprocesos, para determinar superficies y asociar otras capas de datos vectoriales que facilitaron el análisis del contexto y localización de los espacios vacantes.

En la segunda etapa se diseñó un instrumento para caracterizar en sitio los espacios intraurbanos vacantes localizados previamente con sensores remotos. La cédula de descripción de predios se aplicó de manera aleatoria en la colonia Ocotlán, que ocupa el primer lugar en concentración poblacional en la región de estudio, que se compone de seis localidades: La Trinidad Tepehitec, Ocotlán, San Buenaventura Atempan, San Gabriel Cuauhtla, Santa María Ixtulco y Tlaxcala de Xicohténcatl, con la intención de reconocer de manera visual las condiciones del vacío urbano identificado durante el primer momento.

\section{La política nacional de vivienda en México y el mercado inmobiliario}

La ciudad fomenta el intercambio de diversas actividades, ya sean sociales, económicas o ambientales, por mencionar algunas. En consecuencia, el man- 
tenimiento y la preservación de ésta ha adquirido relevancia en las agendas de muchos gobiernos (Tello-Campos y Aguilar-Martínez, 2013).

En la mayoría de las ciudades existen espacios vacíos, baldíos, subutilizados o en desuso que son en potencia útiles para el desarrollo de vivienda. Desde 1970 el tema de los lotes, predios o terrenos baldíos ha sido mencionado en los planes y programas de desarrollo urbano en México, pero no se han diseñado estrategias para su utilización. Garza (1997) afirma que desde la década de 1930 se han establecido un conjunto de leyes, decretos, programas, normas y reglamentos que constituyen la estructura jurídica urbana en México.

En el Programa Nacional de Desarrollo Urbano y Ordenamiento Territorial 2014-2018 (Diario Oficial de la Federación [DOF], 2014) se reconoce que el suelo es el recurso más valioso pero también el más escaso de la ciudad. Además, establece que la política de vivienda seguida en los últimos años generó un proceso expansivo de las ciudades, en específico sobre suelo baldío. El documento destaca que estudios realizados por la Secretaría de Desarrollo Social (SEDESOL) para identificar la disponibilidad de suelo vacante en ciudades, muestran que en las 129 ciudades con más de 50000 habitantes que comprenden el SUN, en 2010 existían 493817 hectáreas de suelo susceptible de incorporarse al desarrollo urbano, de las cuales 86408 hectáreas eran intraurbanas. De acuerdo con el Programa Nacional de Desarrollo Urbano, 207074 hectáreas tienen uso habitacional, de las cuales 41351 son intraurbanas y 165723 se localizan en el primer contorno de crecimiento de los centros de población (DOF, 2014, p. 6).

El suelo intraurbano vacante que puede identificarse de manera precisa al interior de la ciudad, puede utilizarse para el desarrollo de vivienda y, por tanto, "la ocupación de los vacíos intraurbanos de las ciudades y metrópolis, representa una oportunidad para generar un desarrollo urbano denso, ordenado y sustentable, aunque actualmente los gobiernos locales tienen pocos recursos para aprovechar este potencial” (DOF, 2014, p. 7). Prévôt (2000) menciona la existencia de una crisis urbana, situación que da como resultado nuevas formas de urbanización, impulsada principalmente por la fragmentación de las ciudades basada en una premisa básica: la inexistencia de una unificación del conjunto urbano. Por lo tanto, la existencia de un porcentaje alto de vacíos urbanos provoca un constante proceso de expansión de la ciudad en la búsqueda de la exclusividad residencial.

En el año 2014, como parte de la política nacional de vivienda, se buscó no sólo edificar sino también consolidar entornos y ciudades dignas. El objetivo fue transitar hacia un modelo de desarrollo urbano sustentable e inteligente. Parte de los mandatos de la política urbana y de vivienda nacional es el ordenamiento de la ciudad, la buena ubicación de las viviendas, la densificación intraurbana, la concentración de recursos, así como la focalización de acciones. A este respecto, la política del gobierno federal, a través de la Secretaría de Desarrollo Agrario, Territorial y Urbano (SEDATU) y de la CONAVI, dirigió sus esfuerzos hasta el año 2018 al financiamiento público para contribuir a elevar la calidad de vida dentro de la ciudad, promover la redensificación y la construcción de viviendas verticales. Así mismo se buscó evitar la expansión de estas manchas urbanas para reducir los tiempos de traslado de los habitantes al desplazarse 
de los lugares de residencia a sus espacios laborales. En la figura 1 se muestran los PCU creados por la CONAVI para Tlaxcala en 2015, la misma metodología empleada para 384 ciudades que integran el SUN en México y, en 2017, se actualizaron los perímetros de 77 de ellas.

Figura 1. Perímetros de contención urbana (PCU) en Tlaxcala, México, 2015

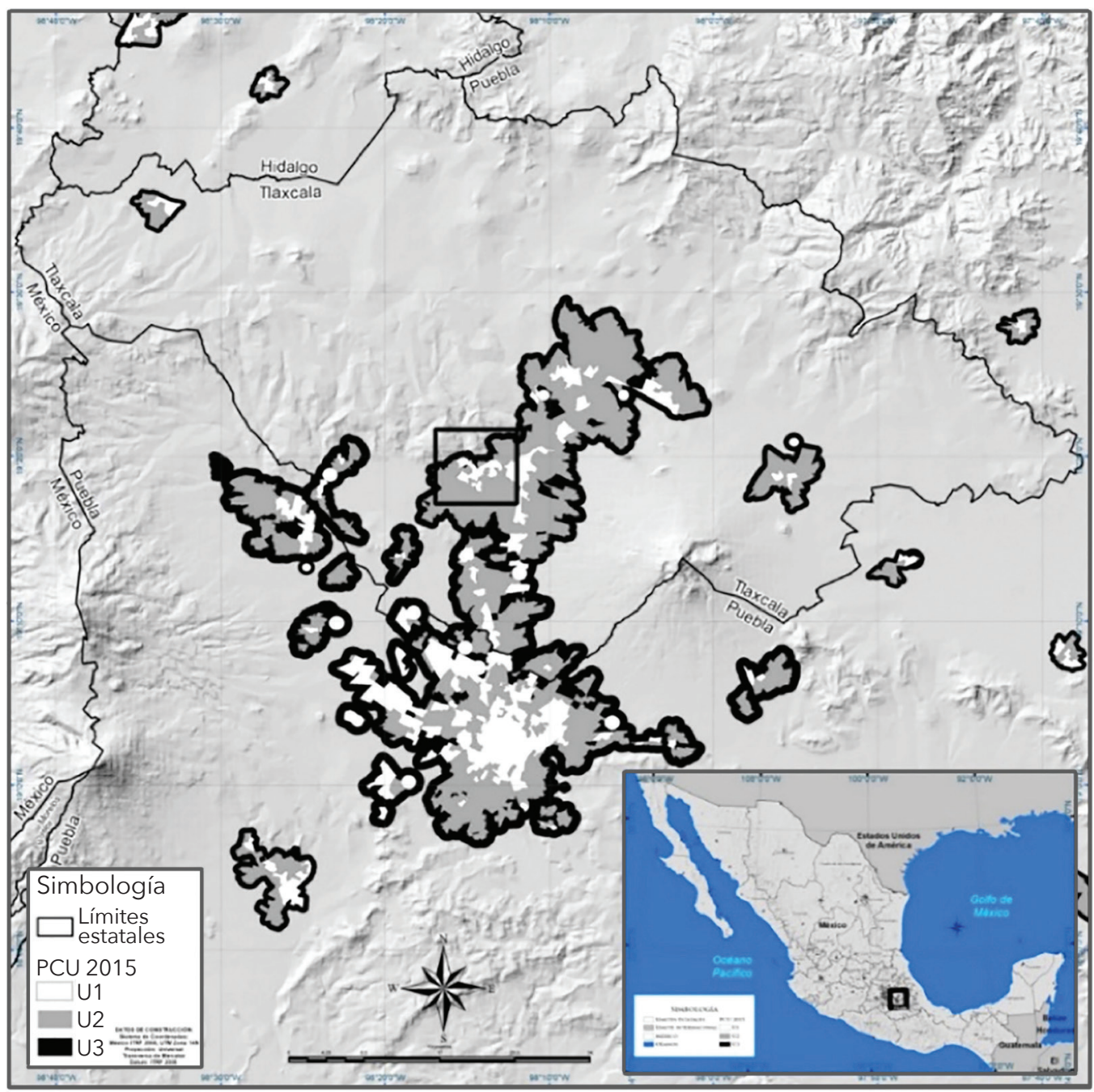

Fuente: elaboración propia con datos de la CONAVI (2015) y el Instituto Nacional de Estadística y Geografía (INEGI, 2015) en software de SIG Arc GIS ver. 10.4.

La estructura de las ciudades y el capital están vinculados en un proceso donde el mercado inmobiliario reproduce en el espacio urbano condiciones que privilegian el capital financiero por encima de la capacidad regulatoria y pla- 
nificadora de las autoridades encargadas del desarrollo urbano y la vivienda. Cuando menos esto ocurre en México, y Tlaxcala no es la excepción. La conformación de la ciudad ha favorecido siempre el capital privado, que también ha estado en manos de quienes detentan el poder político.

El régimen y la regulación urbana no son suficientes en Tlaxcala para explicar las trasformaciones urbanas, pues el poder político y el poder económico en esta región son indisolubles, por lo menos hasta las dos primeras décadas del siglo XXI. Mientras el acceso a la tierra urbana se da por decreto para las clases en el poder (un acceso directo) a través de cambios discrecionales de usos de suelo, el suelo periférico es accesible para la población segregada espacialmente, y los patrones de vivienda colocan la demanda del espacio habitable como dependiente de las políticas de urbanización, condicionadas a un derecho de la clase trabajadora por medio de créditos formales de vivienda (acceso indirecto).

El orden espacial en la configuración de la estructura intraurbana que refiere Abramo (2011), parece predecible, al menos para Tlaxcala, con la amalgamación del capital económico a voluntad del grupo en el poder. El resultado es una diferenciación residencial múltiple, grandes propiedades en zonas residenciales y haciendas para el grupo privilegiado. El resto del espacio habitable se articula para el despliegue de inversiones en comercio, servicios y unidades habitacionales dispersas pero bien reconocidas por sus poseedores: empresarios que se vuelven políticos y políticos convertidos en empresarios.

\section{Por un modelo alternativo de ciudad}

La evolución de los modelos de ciudad es el reflejo de una sociedad que se trasforma y evoluciona de manera constante. Algunos modelos, de corte tradicional, poseen un carácter globalizado y descontextualizado. Sin embargo, han permitido agregar conceptos, instrumentos y metodologías para codificar y reinterpretar la ciudad a partir de sus características específicas en distintas latitudes. Por lo tanto, es necesario reconocer su influencia y contribución para explicar la evolución de la ciudad de Tlaxcala y la zona conurbada.

El origen de las ciudades se remonta al proceso evolutivo del hombre de nómada a sedentario. Mesopotamia dejó vestigios de los primeros asentamientos humanos. Después las ciudades griegas fueron reflejo de una civilización más compleja y fue durante el imperio Romano que apareció el concepto de urbanización (Bazant, 2008, p. 21). La cultura romana fue pionera en diseñar un modelo reticular dentro de la ciudad, formado por dos ejes perpendiculares e intrínsecos en un ángulo recto llamado cardo y decumanus, con un punto central donde se erigían los edificios más importantes. No fue sino hasta la ciudad barroca que la geometría y las proporciones se establecieron como esquemas globales de ordenación, en donde el urbanismo y la arquitectura se unieron al incorporar valores decorativos como elementos esenciales, sobre todo en jardines.

Otro modelo es la ciudad amurallada, que surge en la Edad Media, caracterizada por envolver a su población y ejercer un doble papel de defensa y 
diferenciación, donde se privilegia la sociedad urbana que vive en el interior, de tal forma que ofrece la oportunidad de desarrollar actividades económicas, así como la diversificación de las actividades laborales y un enriquecimiento generalizado (Añíbarro, 2013).

Durante la revolución industrial la estructura interna de la ciudad se modificó tras la aparición de los medios de transporte, y la sobrepoblación provocó la aparición de las clases sociales que se trasladaron hacia la periferia. Owen y Fourier diseñaron durante el siglo XIX pequeños asentamientos utópicos (Frago y Martínez, 2016, p. 3). Mientras tanto, en París, Haussman creó un plan urbanístico reticular cuyo aporte son las uniones que proporcionaron gran fluidez al tránsito de automóviles, al tiempo que se divide la ciudad en barrios administrativos para dar servicios propios. La proyección de un crecimiento futuro permitió la creación de avenidas para una rápida comunicación (Urrieta, 2009, p. 164).

Ildefonso Cerdá propuso uno de los primeros ensanches para la ciudad de Barcelona en 1859, proyectado por un trazado ortogonal, constituido por una red abierta por tramas de calles paralelas al mar y una trama perpendicular que juntas formarían manzanas cuadradas. Este sistema cuadricular elimina el centro urbano y crea múltiples centros con equipamiento donde las personas se desenvuelven todos los días; es decir, busca reconstruir la ciudad desde los espacios que forman parte de la cotidianidad, creando nuevos espacios o aprovechando los abandonados. El proyecto se basa en dos grandes ramos, equipamiento nuevo y reformado, sobre todo en el diseño de espacios dedicados a potenciar las actividades culturales, asociativas o participativas, como centros cívicos, bibliotecas y hogares para ancianos. Según el proyecto, las dos diagonales que cruzan la ciudad (diagonal y meridiana) afectarían las manzanas, que sólo debían ser edificadas por los lados opuestos (Cerdá, 1867).

Hasta estos modelos no hay cabida para la formación de espacio intraurbano vacante de manera intencionada. Éste se va generando conforme se diversifican las actividades de la ciudad y se complejiza su estructura e intensidad en funcionamiento desde el centro hacia la periferia.

Tras la segunda guerra mundial y al enfrentarse a los problemas urbanos y a la escasez de vivienda, Walter Gropius impulsa la idea de organizar el espacio según las funciones para las que se crea (Ulloa, 2008, p. 71). Le Corbusier desarrolla la idea de la ciudad funcional. En 1943 estas ideas fueron sintetizadas en la "Carta de Atenas", que es considerada un hito en la evolución del urbanismo. En dicho documento la ciudad queda zonificada de acuerdo con las necesidades sociales, definidas según una serie de funciones básicas (habitar, trabajar, circular) (Le Corbusier, 1989).

En el modelo de ciudad funcional, existen dos referentes paradigmáticos: Charles Eduard Jeanneret, mejor conocido por su seudónimo Le Corbusier (Fernández, 2000, pp. 575), y Ludwig Hilberseimer (1999). En 1922 Le Corbusier planteó la ciudad en un formato rectangular y la organizó a partir de la infraestructura vial, con una centralidad de carácter administrativo o comercial. En 1927 Ludwig Hilberseimer propone un proyecto llamado ciudad vertical. La iniciativa sugiere evitar la concentración del tránsito de automóviles y la promoción de una mejor ventilación e iluminación. El modelo que propone Hil- 
berseimer se basa en el funcionalismo y el racionalismo. Se aproxima a lo que se busca con el uso de los vacíos urbanos, que es dar vitalidad a la ciudad aprovechando racionalmente el espacio intraurbano promoviendo la compacidad sin que implique concentración.

Otro modelo es la ciudad jardín, que surge como un movimiento urbanístico promovido por Howard en 1902. El fundamento para desarrollar esta ciudad fue la congestión y condiciones de vida precarias en Europa debido a la industrialización. Se procura hacer una ciudad más habitable. Se plantea una valorización de los espacios rurales y de la vida suburbana, cuyo objetivo principal fue la integración de la ciudad y el campo (Montiel, 2015, p. 119).

Unas décadas después de la escuela de Chicago surgieron tres modelos. Uno es el de círculos concéntricos, formulado en 1925 por Burgess. Según el autor las ciudades van creciendo en círculos cada vez mayores en torno a un núcleo central. El modelo de sectores radiantes de Homer Hoyt en 1939 tiene como principal motor la atracción ejercida por las clases sociales con mayor poder adquisitivo. El modelo de núcleos múltiples desarrollado por Harris y Ullman en 1945 afirma que las ciudades contienen más de un centro único, alrededor de los cuales pueden desarrollarse los usos del suelo urbano. Con esta idea se fomenta la expansión bajo el modelo de núcleos múltiples o de tipo policéntrico (Yanes, 2010, p. 25). Esa última condición fue provocada en la ciudad de Tlaxcala a partir de la desconcentración administrativa y generó espacios vacíos en las zonas de transición entre el centro y las nuevas oficinas gubernamentales.

El modelo de ciudad difusa se caracteriza por su monofuncionalidad y baja densidad poblacional. Tiende a diluir la complejidad en la mayor parte de su territorio. Las diversas funciones de la ciudad se separan de manera física para dar lugar a amplios espacios definidos (Borja, 2003, p. 40). Mientras tanto, el modelo de ciudad compacta genera un modelo de ciudad más sostenible y más equilibrada en términos ambientales, lo que significa construir una ciudad más habitable, en donde la salud ambiental se convierta en el mejor indicador de la habitabilidad. Hablar de sostenibilidad urbana es hablar de convivencia y de confort, además de contribuir a salvaguardar el medio ambiente a escala global (Yanes, 2010, p. 26).

Tlaxcala responde a un modelo alternativo en la medida en que, en su calidad de ciudad intermedia, sus dimensiones son manejables en términos administrativos para la instrumentación de medidas por parte de las autoridades estatales y municipales en coordinación. Lo contrario son ciudades como Cancún en Quintana Roo, que rebasa 1.6 millones de habitantes y donde el crecimiento descontrolado, desordenado y anárquico es expansivo y ha sido objeto de análisis y crítica durante las últimas dos décadas. El tamaño de la ciudad y su complejidad son fundamentales, porque pueden rebasar las capacidades de planeación, ordenación, gestión y administración del espacio urbano por parte de las autoridades municipales. En este sentido, la ciudad de Tlaxcala escapa a ese problema, porque tiene dimensiones espaciales y demográficas reducidas y una administración compartida entre el gobierno del estado y el del municipio.

La cantidad de recursos que se suman para las labores de diseño y urbanización planificada pueden contribuir a la implementación de políticas, proyectos 
y medidas para contener la ciudad y a un manejo adecuado de los usos de suelo para un crecimiento equilibrado, ordenado y direccionado, dejando a un lado intereses del capital inmobiliario, cobertura no planificada de servicios públicos e infraestructura innecesaria.

El aporte del estudio, desde la particularidad del caso de Tlaxcala como ciudad intermedia, puede ser útil para espacios con características rurales o urbanas en las dimensiones de esta tipología de ciudades. La posibilidad de llevar a cabo la investigación no se divorcia de la coordinación intergubernamental, pero su mayor valor radica en la capacidad de ordenar, planificar, legislar, gestionar y administrar el suelo en favor del aprovechamiento de espacios intraurbanos vacantes. Lo anterior ubica a la ciudad de Tlaxcala en vías de concebirse como un modelo de ciudad intermedia que aprovecha los recursos administrativos y las ventajas de una eficaz administración, ordenación, gestión y planificación del espacio intraurbano, poniendo límites a la expansión a través de la optimización del uso del suelo disponible atrapado y subutilizado en el interior de la ciudad.

\section{La región de análisis}

La ciudad de Tlaxcala es la capital del estado con el mismo nombre y la más poblada de la entidad federativa. Su número de habitantes, según datos de la Encuesta Intercensal 2015 (INEGI, 2015a), asciende a 95 051, cifra que se ha incrementado mucho a raíz del proceso de conurbación de cinco municipios: Chiautempan, Totolac, Apetatitlán, Panotla y La Magdalena Tlaltelulco.

A pesar de que la ciudad de Tlaxcala todavía presenta dimensiones espaciales y niveles de concentración poblacional que la colocan como una ciudad intermedia, los efectos de la política nacional de vivienda no se han hecho esperar. Desde finales del siglo pasado, ante la severa expansión física de las ciudades y la urbanización periférica colosal, las estrategias de la política de vivienda han priorizado el desarrollo urbano intensivo con miras a una ciudad compacta, ${ }^{1}$ lo que ha fijado el interés de la política nacional en la recuperación de los espacios vacantes de la ciudad, el repoblamiento de los centros, la redensificación y la regeneración urbana para combatir el déficit de vivienda (Delgadillo, 2016, p. 112), ya que de las necesidades humanas, contar con una vivienda es una de las más importantes y valoradas en cualquier sociedad del mundo (Tejeda y Lara, 2018, p. 4).

Construir una ciudad compacta y ordenada demanda un largo proceso de revalorización del espacio urbano. Lo que fueron lotes baldíos, zonas olvidadas o viviendas en desuso, hoy son vistos como un componente vital que debe ir en armonía con el resto del tejido social y urbano. Lograr esa condición y alcanzar

1 El estudio "México compacto", publicado por la Comisión de Vivienda del Senado de la República en el año 2014, y el mismo Plan Nacional de Desarrollo Urbano y Ordenamiento Territorial 2014-2018 expresan la necesidad de controlar la expansión de las ciudades a partir de la promoción y el reemplazo de viviendas en zonas interiores mediante el uso del suelo intraurbano disponible y la densificación del espacio urbano. 
la categoría de compacidad puede llegar a convertirse en una utopía asociada con la condición social de las clases que la habitan (Lombard, 2015, p. 125).

La atención se centra en los procesos de dispersión urbana y recuperación de los centros poblados, en especial zonas de uso común, lo que en México se ha denominado Programa de Rescate de Espacios Públicos; pero también es importante la redensificación que, para efectos del déficit del espacio habitable, permite contribuir a los procesos de repliegue de la ciudad y a una resiliencia interna que facilita la regeneración del espacio construido en zonas con potencial para vivienda. Si lo anterior sucede conforme lo esperaba la CONAVI a través de su política nacional de vivienda y trasciende en el estado de Tlaxcala en los próximos años, se estará frente a una verdadera metamorfosis urbana, es decir, una necesaria evolución histórica de las ciudades con una urgente articulación al interior de la ciudad, de manera que la dispersión y la expansión desordenadas sean contrarrestadas por el principio de compactación.

Contrario a lo anterior, están las ciudades dispersas y difusas, entendidas como urbes con baja densidad de viviendas y de habitantes que se explican sobre todo por el dinamismo y los tipos predominantes de sus actividades económicas. Son ciudades intermedias cuyas características determinan en gran medida la especulación del suelo (Mattos, Fuentes y Link, 2014), que termina por reconfigurar los espacios urbanos con baja densidad de vivienda. Esto sucedió en la periferia de la ciudad de Tlaxcala después de la desconcentración de oficinas del gobierno federal (delegaciones) y del gobierno del estado en los últimos 20 años, lo que dio como resultado la creación de zonas habitacionales, autoconstrucción de vivienda y un sinnúmero de predios disponibles sobre todo para uso residencial que utilizaron algunas empresas y particulares para hacerse de terrenos cercanos a las localidades de Apetatitlán, Tepehitec, Metepec, Acuitlapilco, Chiautempan, Camino Real, Tlatempan, Ocotlán, Volcanes, Atlahapa, Atempan y Cuauhtla. Todo esto ocurrió de manera desordenada y sin una actualización de la carta síntesis urbana que se ha mantenido vigente desde 1983; desde entonces no se volvió a actualizar ni se incorporaron medidas para contener la ciudad.

El objetivo central de los PCU era frenar el proceso de expansión física de las ciudades, donde el primer perímetro (PCU1), de los tres que componen los PCU, está ubicado al interior de la ciudad. Esta microrregión se convierte en la unidad de análisis del presente trabajo. Este primer polígono interno se incorporó en formato shapefile en software de sistemas de información geográfica (SIG), en particular en Arc GIS versión 10.4. Se añadieron las capas de municipios y localidades en el mismo formato para identificar aquellas que están sobrepuestas de manera parcial o total sobre el PCU1. Así mismo se vincularon datos socioeconómicos y se realizaron geoprocesos de corte, intersección y asignación espacial sobre la zona urbana a partir de los shapefiles que convergen en el PCU1, municipios y localidades en formato de polígono. A partir de esta consideración metodológica, se construyó la región de análisis que tiene como centro la ciudad de Tlaxcala.

Los antecedentes del proceso de urbanización de la ciudad de Tlaxcala como nodo de la región de estudio se remontan a su fundación en la primavera de 
1522, cuando cuatro señores prehispánicos (Ocotelulco, Tepeticpac, Tizatlán y Quiahuixtlán) fundaron la capital. Ellos se asentaron en la ribera del río Zahuapan y comenzaron a edificar casas, dejando espacios para plazas y calles. Años después, ya como centro urbano, tenía una plaza principal que servía de tianguis (mercado) en su centro, y en sus portales estaban las tiendas de los españoles.

En 1862, la ciudad creció. Tenía como subcentros las iglesias de San Francisco al sureste y la de San José junto al Palacio de Gobierno, así como varias manzanas sin construir, pero ya con una traza indicada. Entre 1853 y 1884 el ayuntamiento construyó aceras, lavaderos públicos, caminos, puentes y realizó trabajos de ordenamiento urbano en la ciudad (Velasco y Bustamante, 2006, p. 20).

Un aspecto que explica el proceso de urbanización lento de la ciudad de Tlaxcala, es su topografía. Desde su fundación creció en los contornos geográficos que el valle le imponía y, a pesar de los lomeríos que la rodean en casi todas las direcciones, encontró en el noreste un crecimiento natural hacia el municipio de Santa Ana Chiautempan. Aun tras desempeñarse como centro de muchas operaciones administrativas, el crecimiento poblacional no fue acelerado. Entre 1920 y 1960 se triplicó su población: pasó de 2069 a 7 545. En otros municipios colindantes, como el de Chiautempan, casi se cuadruplicó: de 3888 a 11296 habitantes. Las condiciones de relieve y las dificultades para la expansión de la ciudad provocaron que buena parte del equipamiento e infraestructura se trasladara a municipios colindantes.

Sacar los servicios administrativos del centro y colocar oficinas en la periferia fue una estrategia que tuvo como resultado que entre 1980 y 1990 la ciudad de Tlaxcala tuviera el crecimiento poblacional más rápido del estado, con una tasa de $10.7 \%$ y 50486 habitantes, lo cual la convirtió en el centro urbano más poblado de la entidad federativa.

La topografía y desconcentración de los servicios de la administración pública del gobierno del estado fueron elementos que facilitaron la estructuración de la ciudad en tres direcciones: hacia el nororiente con el municipio de Apetatitlán de Antonio Carvajal, hacia el oriente con el municipio de Santa Ana Chiautempan y hacia el sur con la localidad de Acuitlapilco. Esta desconcentración de actividades que liberaron el centro de la dinámica, permitió que la ciudad de Tlaxcala presentara un aumento constante y permanente de la población, aunque en una proporción muy pequeña. Al mismo tiempo explica por qué no se amplió de manera significativa el tamaño de la ciudad.

A diferencia de otras ciudades donde el proceso de crecimiento es radiocéntrico o expansivo, en Tlaxcala la necesidad de sacar los servicios de un espacio estrecho donde radicaban todas las instituciones públicas de la entidad federativa, tuvo como efecto inmediato la urbanización de manera natural de la periferia cercana, pues la gran mayoría de instituciones públicas se localizaron en un radio de influencia de dos kilómetros, mientras que la ciudad de Tlaxcala en su morfología apenas ocupaba dos de largo por uno de ancho.

La distancia entre las zonas de desconcentración administrativa y la ciudad de Tlaxcala generó espacios desocupados que con el paso de los años se urbanizaron de manera acelerada, para conformar lo que en la actualidad es la zona conurbada de la ciudad, integrada por algunas localidades y municipios colin- 
dantes. Los espacios intraurbanos vacantes localizados en esas zonas de transición pueden ser aprovechados para promover la densificación en zonas que, por naturaleza de uso de suelo, gozan de todos los servicios y fomentar su ocupación con viviendas. Así, se daría un paso hacia la compacidad de la ciudad.

Para mayor precisión, la región de estudio se localiza en el centro de la ciudad capital en el municipio de Tlaxcala, lugar donde está situado el PCU1. La CONAVI definió los PCU1 como espacios donde puede haber una o más localidades urbanas. Sus principales características son la alta concentración poblacional y las fuentes de empleo dentro del perímetro. Para efectos de este trabajo, la región de estudio está compuesta por seis localidades, pertenecientes al municipio de Tlaxcala, que están consideradas dentro del primer perímetro de contención urbana (PCU1). Las localidades que integran la región de estudio son: La Trinidad Tepehitec, Ocotlán, San Buenaventura Atempan, San Gabriel Cuauhtla, Santa María Ixtulco y Tlaxcala de Xicohténcatl. En la figura 2 se muestran la región y los rangos de población de las localidades que la componen.

Figura 2. Delimitación de la región de estudio y rangos de población por colonias

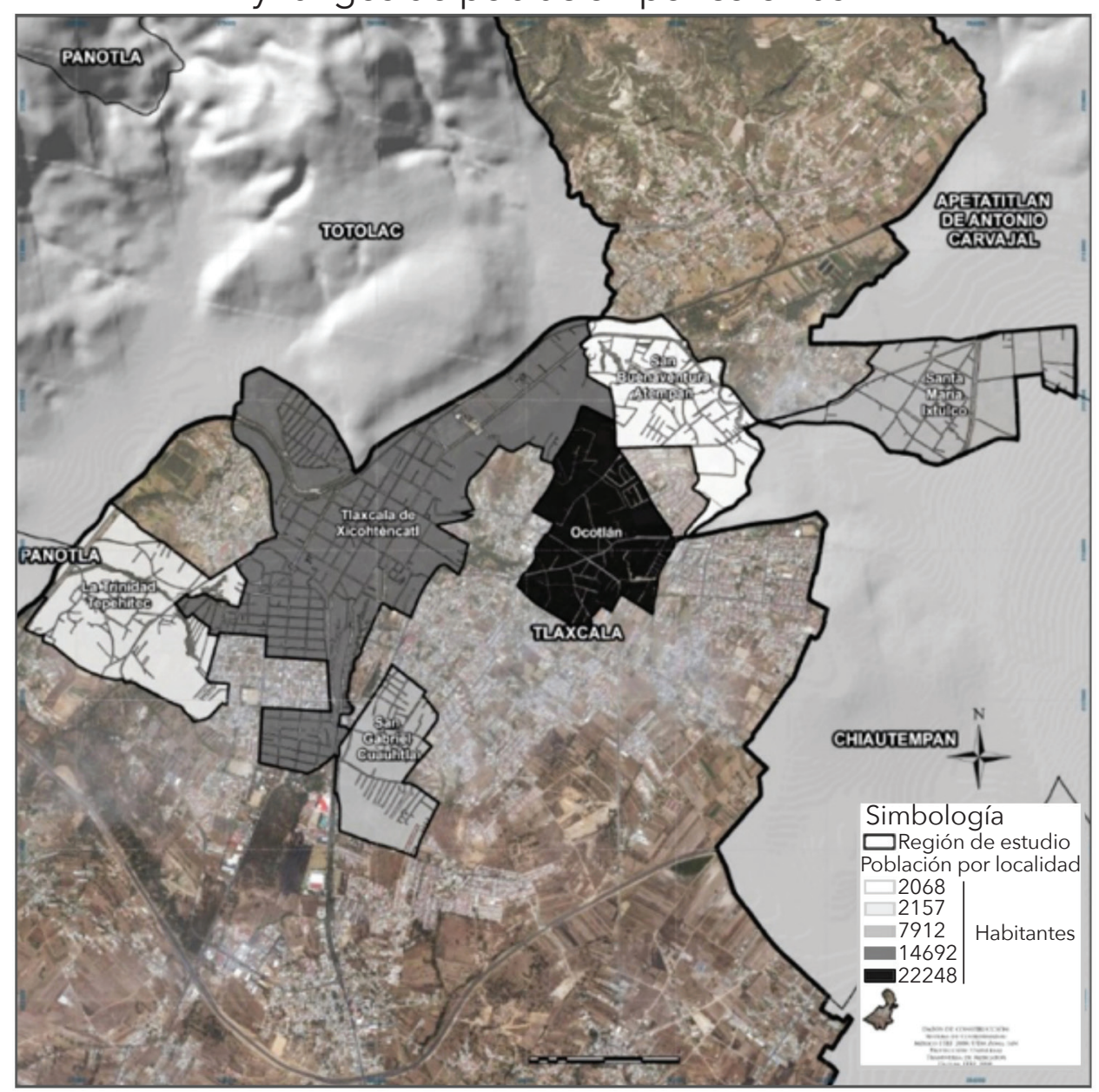

Fuente: elaboración propia con datos de la CONAVI (2015) y del INEGI (2015 b) en software de SIG Arc GIS versión 10.4. 
En materia de infraestructura, equipamiento y cobertura de servicios públicos, se ha encontrado que la mayor cantidad de ellos se localiza en el polígono de la colonia Tlaxcala de Xicohténcatl o también llamada colonia Centro, que es donde se localiza el centro histórico. Le sigue la colonia Ocotlán, que concentra la mayor cantidad de población. Lo anterior se ha convertido en un patrón muy identificable debido a la poca cobertura de servicios públicos en las zonas periféricas y a la concentración poblacional en las zonas más ricas o de alto ingreso económico de las ciudades (Pérez-Campuzano, 2010, p. 146).

Derivado del análisis espacial, la relación de viviendas habitadas tiene una distribución dispersa y no necesariamente coincide con la cantidad de población, ya que hay distintos niveles de hacinamiento. En la colonia Centro se muestra mayor concentración de población. No obstante, en relación con las viviendas habitadas, sólo la colonia Ocotlán se encuentra en el rango más alto; el resto presenta un número bajo de viviendas, hecho que puede ser originado por la alta cantidad de establecimientos comerciales y de servicios que ofrecen empleo. Es decir, las personas no habitan en esos espacios, sólo laboran en el sector predominantemente terciario. Lo anterior explica lo que Fuentes (2009) establece como una separación espacial entre zonas de empleo y áreas habitacionales, lo cual se traduce en incremento de las distancias entre el trabajo y el espacio habitable.

\section{Suelo intraurbano vacante en la región de estudio}

A partir de diversas técnicas de teledetección ${ }^{2}$ y con la suficiente resolución espacial de las imágenes de satélite, es posible la identificación de los espacios vacantes en la región de estudio que es de tipo urbano y con ocupación habitacional. La base del análisis central de esta investigación consiste en identificar los espacios vacantes con potencial para vivienda. Los espacios vacíos que se caracterizaron son, por lo general, predios sin construcción que cuentan por lo menos con un acceso por cualquiera de sus lados. Así mismo se advierte el supuesto de que ninguno tiene restricción de construcción, impedimento legal de uso o riesgos que impidan la edificación. La característica común a todos los predios identificados es que han quedado en estado de abandono o desuso dentro de zonas que gozan de servicios, equipamiento e infraestructura.

Con la técnica de fotointerpretación espacial, se digitalizaron 213 espacios vacantes que presentaron características con potencial para vivienda. De éstos, la verificación en campo permitió corroborar que 100\% cuenta con alumbrado público, 97\% tiene vías de comunicación pavimentadas, guarniciones, banquetas y agua potable, y $94 \%$ telefonía fija y sistema de televisión por cable. Todos estos servicios están disponibles en el espacio donde se hizo un recorrido para su verificación ocular.

2 Es una geotecnología que se encarga de obtener información a distancia a través del análisis espacial de estructuras matriciales, compuestas por pixeles para fotoidentificar elementos en el territorio. Puede ser por digitalización manual o automática, la primera mediante la fotointerpretación del espacio físico de la ciudad y la automática, mediante una clasificación no supervisada a partir de geoprocesos. 
Figura 3. Características del espacio vacante identificado en la región de estudio

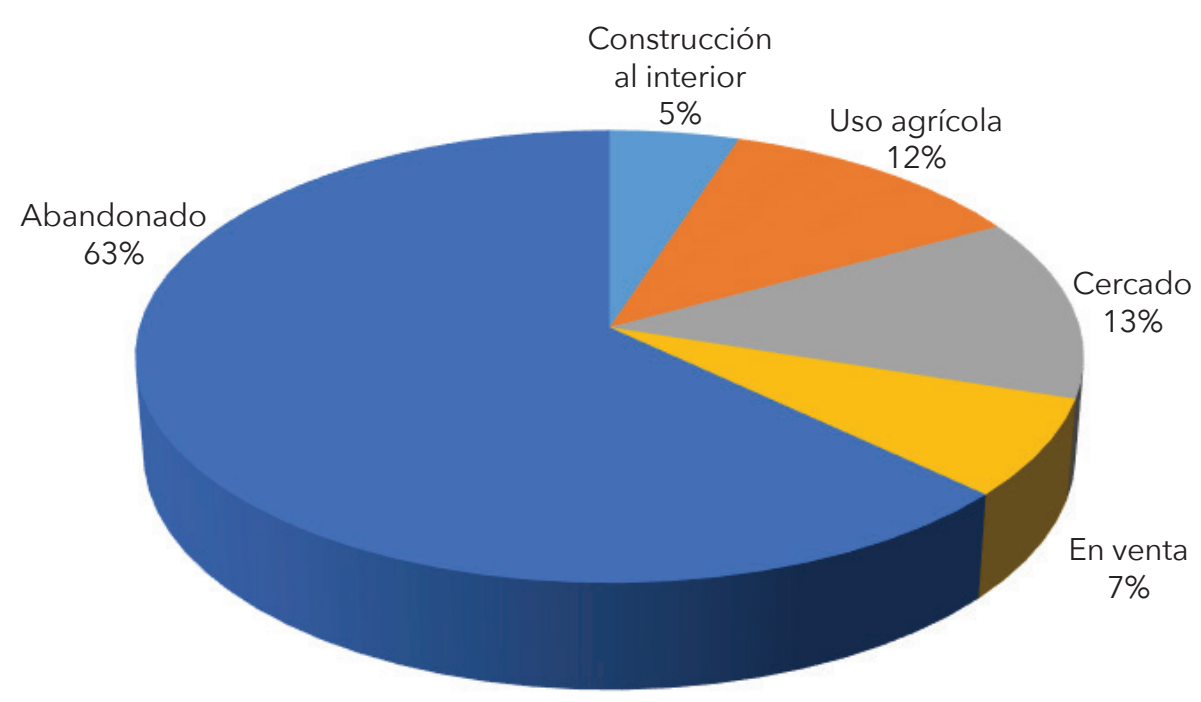

Fuente: elaboración propia con datos de guía de observación.

En relación con el contexto y entorno que presenta el espacio vacante, se corroboró que $77 \%$ de los espacios cuenta con comercios y servicios cercanos (dentro del perímetro de la manzana analizada). En relación con la infraestructura y equipamiento, $76 \%$ cuenta con acceso inmediato a escuelas, parques y centros de salud y $80 \%$ tiene cobertura de servicio de trasporte público para la movilidad.

También se hizo un análisis espacial de distribución radial por colonias, y se concluyó que la colonia con mayor número de espacios vacantes no necesariamente es la que tiene mayor potencial para ser densificada. Ejemplo de lo anterior es que en la colonia Centro se localizan 97 espacios vacantes del total en la región de estudio, que fueron 213 , lo que representa $54.54 \%$; sin embargo, sólo cubre $10 \%$ de la superficie total que ocupan los espacios identificados en las seis localidades de la región estudiada (La Trinidad Tepehitec, Ocotlán, San Buenaventura Atempan, San Gabriel Cuauhtla, Santa María Ixtulco y Tlaxcala de Xicohténcatl). Lo anterior significa que los vacíos urbanos del centro de la ciudad son de menor tamaño en comparación con los que se localizan de manera progresiva y radiocéntrica hacia la periferia; es decir, a medida que nos alejamos del centro, mayor es el tamaño del suelo intraurbano vacante.

La colonia Ocotlán muestra un elevado número de viviendas y una alta concentración poblacional. Las cifras advierten escasa posibilidad de hallar espacios vacantes disponibles para vivienda. No obstante, se localizaron 63 espacios vacíos, que representan $26 \%$ del área total; por lo tanto, es una colonia con 
posibilidades de densificarse y albergar un gran número de habitantes adicionales. Además, tiene la ventaja de contar con infraestructura, establecimientos, servicios y proximidad a la ciudad capital.

Tabla 1. Vacíos identificados por localidad

\begin{tabular}{|l|c|c|c|}
\hline \multicolumn{1}{|c|}{ Colonia } & $\begin{array}{c}\text { Número } \\
\text { de vacíos }\end{array}$ & $\begin{array}{c}\text { Metros } \\
\text { cuadrados }\end{array}$ & $\begin{array}{c}\text { Porcentaje } \\
\text { del área total }\end{array}$ \\
\hline La Trinidad Tepehitec & 12 & 585708.06 & 0.39 \\
\hline Ocotlán & 63 & 384957.86 & 0.26 \\
\hline San Buenaventura Atempan & 32 & 189669.35 & 0.13 \\
\hline San Gabriel Cuauhtla & 5 & 91755.95 & 0.06 \\
\hline Santa María Ixtulco & 4 & 95000.65 & 0.06 \\
\hline Tlaxcala de Xicohténcatl & 97 & 156793.48 & 0.1 \\
\hline Totales & 213 & 1503885.34 & 1 \\
\hline
\end{tabular}

Fuente: elaboración propia a partir de digitalización manual en Google Earth Pro.

La distribución de estos espacios por colonias permite jerarquizarlos a partir de su potencial para vivienda. Sus cualidades ofrecen a los habitantes los servicios básicos y complementarios para el desarrollo de sus actividades diarias. Dotan de establecimientos comerciales las zonas habitacionales cercanas, reducen el empleo de vehículos, facilitan la movilidad peatonal y reducen impactos negativos al medio ambiente.

Al interior de los PCU, que en superficie representan una porción relativamente pequeña dentro del municipio de Tlaxcala, se han detectado espacios suficientes para densificar colonias urbanas, como La Trinidad Tepehitec, Ocotlán y San Gabriel Cuauhtla. Ocotlán presenta condiciones para perfilar un modelo de planificación que considere una estrategia apoyada en la política nacional de vivienda señalada por la CONAVI y frenar el crecimiento desordenado de la ciudad a partir de los perímetros de contención. Además, con la identificación de espacios vacantes es posible emprender medidas de planificación urbana en la ciudad de Tlaxcala y aspirar en principio a sentar las bases para la construcción de una ciudad compacta.

\section{La densificación en la región de estudio}

El ritmo de crecimiento, concentración y distribución de la población es fundamental en la consolidación de la dinámica y la estructura urbanas. De forma natural, los centros urbanos actúan como imán: atraen personas que buscan oportunidades para mejorar su nivel de vida, lo que da como resultado un crecimiento acelerado de la población urbana, la multiplicación de actividades económicas y, en consecuencia, la expansión física de la ciudad. 
Las grandes distancias y la baja densidad tienden a aumentar el parque vehicular privado y fomentar el uso intensivo del automóvil. En cambio, con el modelo de ciudad compacta se tienen diversas ventajas, porque la propuesta se caracteriza por el uso mixto del suelo (para uso comercial, infraestructura o vivienda), en donde se generan flujos de tráfico multidireccionales, lo cual permite un uso más eficiente de la infraestructura, ya que las áreas residenciales, los lugares de trabajo y los servicios se encuentran distribuidos de manera más uniforme.

Figura 4. Localización de espacios vacantes distribuidos por radios de influencia en la región de estudio

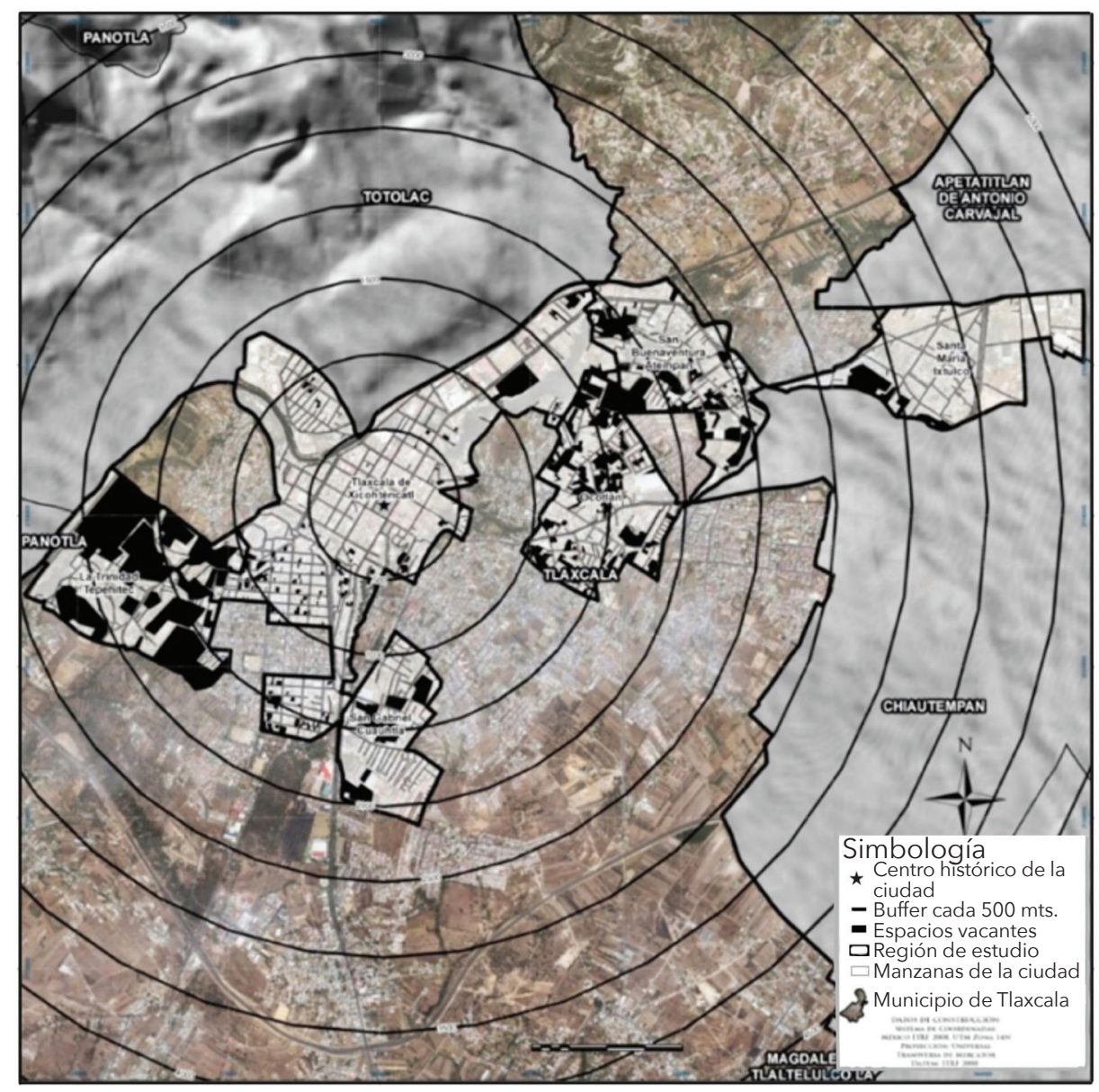

Fuente: elaboración propia con base en análisis espacial en software de SIG, datos de la CONAVI (2015) y de INEGI (2015b).

A partir del modelo anterior, se realizó un análisis basado en el supuesto de fomentar el uso mixto del suelo y así distribuir, a través de los espacios vacantes, áreas residenciales, lugares de trabajo y de servicios. Se tomó como punto de referencia el centro histórico de la ciudad de Tlaxcala, toda vez que 
los centros urbanos tiene un efecto de polo: provocan la concentración poblacional, así como servicios, infraestructura, equipamiento y áreas de trabajo. Se establecieron radios de influencia cada 500 metros bajo el supuesto de una ciudad funcional y se tomó esa distancia como rango promedio de desplazamiento natural de las personas en bicicleta para realizar sus actividades cotidianas.

El análisis de estos radios de influencia sobre los espacios vacantes contenidos en la región de estudio permite observar las ventajas de estos lugares con posibilidades de densificación dada su cercanía al núcleo central.

Tabla 2. Vacíos identificados por localidad a distintos radios de influencia

\begin{tabular}{|c|c|c|}
\hline Vacíos identificados & Localidad & Radio de influencia (metros) \\
\hline 14 & Tlaxcala de Xicohténcatl & \multirow{2}{*}{500} \\
\hline 3 & La Trinidad Tepehitec & \\
\hline 17 & \multicolumn{2}{|c|}{ Subtotal } \\
\hline 44 & Tlaxcala de Xicohténcatl & 1000 \\
\hline 44 & \multicolumn{2}{|c|}{ Subtotal } \\
\hline 36 & Ocotlán & \multirow{4}{*}{1500} \\
\hline 24 & Tlaxcala de Xicohténcatl & \\
\hline 4 & La Trinidad Tepehitec & \\
\hline 3 & San Gabriel Cuauhtla & \\
\hline 67 & \multicolumn{2}{|c|}{ Subtotal } \\
\hline 16 & Tlaxcala de Xicohténcatl & \multirow{5}{*}{2000} \\
\hline 4 & San Buenaventura Atempan & \\
\hline 25 & Ocotlán & \\
\hline 3 & La Trinidad Tepehitec & \\
\hline 2 & San Gabriel Cuauhtla & \\
\hline 50 & \multicolumn{2}{|c|}{ Subtotal } \\
\hline 26 & San Buenaventura Atempan & \multirow{2}{*}{2500} \\
\hline 1 & La Trinidad Tepehitec & \\
\hline 27 & \multicolumn{2}{|c|}{ Subtotal } \\
\hline 2 & San Buenaventura Atempan & \multirow{2}{*}{3000} \\
\hline 2 & Ocotlán & \\
\hline 4 & \multicolumn{2}{|c|}{ Subtotal } \\
\hline 3 & Santa María Ixtulco & 3500 \\
\hline 3 & \multicolumn{2}{|c|}{ Subtotal } \\
\hline 1 & Santa María Ixtulco & 4000 \\
\hline 1 & \multicolumn{2}{|c|}{ Subtotal } \\
\hline 213 & \multicolumn{2}{|c|}{ Total } \\
\hline
\end{tabular}

Fuente: elaboración propia con datos de la CONAVI (2017). 
Con la proximidad al núcleo central, el resultado muestra que el contorno con mayor número de espacios vacantes se encuentra a una distancia de 1500 metros, integrado por cinco localidades, que son Tlaxcala de Xicohténcatl, San Buenaventura Atempan, Ocotlán, La Trinidad Tepehitec y San Gabriel Cuauhtla. El resultado es que los contornos más cercanos al núcleo central cuentan con poca área disponible para vivienda, dado que concentran establecimientos y servicios.

Aunque el modelo de crecimiento que presenta la ciudad de Tlaxcala es horizontal, la identificación de espacios con potencial para vivienda es baja en el contorno más alejado. No obstante, hay áreas disponibles de gran tamaño y, por lo tanto, la oportunidad de densificar al interior de la región de estudio es viable.

Con la aproximación espacial que aparece en la figura 4, se advierte la concentración de espacios vacantes por proximidad al núcleo central, con lo cual es posible identificar rangos y distancias donde se encuentra la mayor cantidad de espacios con potencial para densificar la ciudad, de tal forma que se puede planificar una distribución uniforme según las necesidades en cada PCU.

Si los vacíos urbanos pertenecen a una zona con concentración poblacional que se encuentra alejada del núcleo central, habrá que considerar el acceso a servicios y fuentes laborales, de tal modo que el uso mixto del suelo ofrezca a sus habitantes la posibilidad de permanecer en la zona y aprovechar la cercanía para facilitar su traslado. Lo anterior debe complementarse con estudios de movilidad que refuercen la propuesta, pertinencia y alcances del modelo.

\section{Conclusiones}

La ciudad dispersa es una constante en las ciudades de México. Se caracteriza por la expansión física desordenada y sin control hacia las periferias urbanas en busca de un espacio habitable. La centralidad es un indicador de estructura urbana que define en la ciudad de Tlaxcala la distribución espacial y la jerarquía de sus actividades económicas. Por eso resulta fundamental la administración, planificación, ordenación y gestión del suelo urbano, de modo que la población tenga acceso a vivienda con precios acorde con sus ingresos y que puedan preverse los procesos expansivos.

Al agrupar los espacios vacantes por áreas y analizarlos de manera espacial en relación con su entorno y sus peculiaridades, se encontraron características comunes. Con el tiempo, estos espacios vacantes son ocupados con nuevas construcciones donde la compactación interna en la ciudad parece improcedente. No obstante, la cantidad de vacíos urbanos dispuestos en la zona de estudio es una razón suficiente y al mismo tiempo un desafío para validar la pertinencia del modelo urbano de ciudad compacta.

El aporte del trabajo sugiere estudiar más a fondo las ventajas de las ciudades intermedias ante la difícil tarea de controlar su crecimiento a partir de medidas de contención basadas en políticas para la delimitación de perímetros destinados para vivienda, industria, comercio y servicios. Tlaxcala, como 
muchas otras ciudades intermedias que se ubican en espacios todavía rurales, presenta condiciones propicias para intervenirlas con medidas de planificación territorial y diseño urbano de dimensiones manejables, debido a su tamaño de población en zonas centrales y periféricas. La estructura de ciudades de estas dimensiones permite todavía direccionar el destino morfológico y funcional con la intención de densificar los espacios disponibles al interior.

Inventariar el suelo intraurbano vacante es una necesidad urgente, porque permite analizar su distribución espacial, su vocación y su potencial para promover la densificación de vivienda. En la medida en que el presente estudio aporte una visión de la estructura existente, será posible detectar patrones de distribución y con ello definir criterios precisos para la densificación planificada de las ciudades.

La especulación inmobiliaria impidió el uso adecuado de los espacios vacíos. El reto es reutilizarlos para densificar y evitar la expansión de la ciudad. Para avanzar en esta idea, es necesario entender que la densificación no sólo significa lograr un determinado nivel de aglomeración, sino que además están en juego criterios funcionales, de mercado, de localización y de organización de la estructura interna de la ciudad.

El inventario realizado en esta investigación permitió identificar los vacíos urbanos con potencial para cubrir las necesidades de vivienda. Sin embargo, no existen medidas que incentiven a los propietarios a dar a esos espacios un uso que contribuya a mejorar la estructura y el funcionamiento de la ciudad y a advertir criterios básicos para un perfil de ciudad compacta.

El uso potencial de los espacios vacantes estudiados en el presente trabajo permite observar que sus características ofrecen opciones y posibilidades de desarrollo urbano local. Su condición no tiene restricciones para una articulación con su entorno inmediato en la ciudad. Una adecuada intervención basada en la radiografía de su localización puede conducir a procesos de planificación ordenada del espacio urbano.

Con estos aportes, la disciplina urbanística adquiere un valor positivo para la recuperación de los espacios vacantes. Son los actores con conciencia de la situación problemática (expansión acelerada y descontrolada de la ciudad) quienes pueden promover acciones para contrarrestar la especulación todavía latente, sobre todo en las zonas de Atlahapa y en el libramiento de la ciudad, también llamado Anillo Periférico, cuya construcción fomentó el acaparamiento de tierras de uso agrícola, el desuso y el deterioro del espacio habitable en la ciudad. Cuando las voluntades de los dueños de predios vacantes, habitantes y gobiernos se conjunten en acuerdo positivo, será posible articular una propuesta que aliente los principios de una ciudad compacta.

La escala de análisis de una ciudad relativamente pequeña como Tlaxcala, que tiene como promotor de la política urbana y capital empresarial al mismo grupo en el poder, no permite reconocer una expansión y compactación o ciudad COM-FUSA, como la llama Abramo (2011), compacta y difusa a la vez. Más bien se tiene una particularidad: la invasión de un capital foráneo proveniente de la cercana ciudad de Puebla, que está tomando la periferia de la ciudad de Tlaxcala como una ciudad dormitorio ante la creación de infraestructura de 
alta velocidad y la llegada de empresas de capital internacional con alto impacto regional (AUDI y Volkswagen). Lo anterior permite ver el suelo intraurbano vacante como una alternativa de vivienda al interior de la ciudad, cuando menos para los tlaxcaltecas, que tienen un fuerte rechazo al influjo del exterior.

\section{Referencias}

Abramo, P. (2011). La producción de las ciudades latinoamericanas: mercado inmobiliario y estructura urbana. Quito: Olacchi. Recuperado de https:// biblio.flacsoandes.edu.ec/libros/129057-opac

Álvarez de la Torre, G. B. (2017). Morfología y estructura urbana en las ciudades medias mexicanas. región y sociedad, 29(68), 153-191. doi: 10.22198/ rys.2017.68.a872

Añíbarro, J. (2013). Las cuatro villas de la costa de la mar en la Edad Media. Conflictos jurisdiccionales y comerciales (Tesis doctoral). Recuperado de https: / / repositorio.unican.es/xmlui/bitstream/handle/10902/3343/Tesis\%20 JAR.pdf?sequence=1\&isAllowed=y

Araque, J. (2011). Ciudad-sutura: operaciones sobre el vacío urbano. Caso de estudio: sector oeste de la ciudad de Barquisimeto, Venezuela. Recuperado de https://www.fau.ucv.ve/trienal2011/cd/documentos/cs/CS-3.pdf

Araujo, A. de. (2004). Tierra vacante en las ciudades de América Latina: desafíos y oportunidades. Ponencia presentada en abril de 1999 en el Seminario Internacional sobre Tierra Vacante. Río de Janeiro, Brasil. Recuperado de https://www.lincolninst.edu/sites/default/files/pubfiles/tierra-vacante-en-las-ciudades-de-america-latina-full.pdf

Arteaga Botello, N. (2016). Política de la verticalidad: drones, territorio y población en América Latina. región y sociedad, 28(65), 263-292. doi: 10.22198/ rys.2016.65.a363

Bazant, J. (2008). Espacio urbano: historia, teoría y diseño. México: Limusa.

Bishop, P., y Williams, L. (2016). El ideal de la permanencia. En M. Fernández y J. Gifreu (coords.), El uso temporal de los vacíos urbanos (pp. 15-56). Barcelona: Diputación de Barcelona.

Borja, J. (2003). La ciudad conquistada. Madrid: Alianza Editorial.

Cavalieri, M., Gerscovich, A., y Wainstein-Krasuk, O. (2010). Gestión social de vacíos urbanos en la Ciudad Autónoma de Buenos Aires. Un caso de estudio. Pampa, 1(6), 59-87. doi: 10.14409/pampa.v1i6.3177

Cerdá, I. (1867). Teoría general de la urbanización y aplicación de sus principios y doctrinas a la reforma y ensanche de Barcelona. Madrid: Imprenta Española.

Clichevsky, N. (ed.). (2002). Tierra vacante en ciudades latinoamericanas. Toronto: Lincoln Institute of Land Policy.

Comisión Nacional de Vivienda (CONAVI). (2015). Perímetros de contención urbana en formato shapefile. Ciudad de México: Comisión Nacional de Vivienda. Recuperado de http://www.conavi.gob.mx/datos-abiertos 
Comisión de Vivienda del Senado de la República. (2014). México compacto: las condiciones para la densificación urbana inteligente en México. Cámara de Senadores del H. Congreso de la Unión. Recuperado de https: / / www. senado. gob.mx/comisiones/vivienda/docs/mexico_compacto.pdf

Delgadillo, V. (2016). Ciudad de México, quince años de desarrollo urbano intensivo: la gentrificación percibida. Revista INVI, 31(88), 101-129.

Diario Oficial de la Federación (DOF). (2014). Programa Nacional de Desarrollo Urbano y Ordenamiento Territorial 2014-2018. Secretaría de Desarrollo Agrario, Territorial y Urbano, Ciudad de México, México. Recuperado de http:// dof.gob.mx/nota_detalle.php?codigo=5342867\&fecha=30/04/2014

Fausto, A. (2005). Conceptos relacionados con los espacios vacantes en la ciudad. Documento de trabajo, Centro de Estudios Metropolitanos, CUAAD, Universidad de Guadalajara, Guadalajara, Jalisco. Recuperado de https:// es.slideshare.net/Urba2014/fausto-brito-adriana-conceptos-relacionados-con-los-espacios-vacantes-en-la-ciudad

Fausto, A., y Rábago, J. (2001). ¿Vacíos urbanos o vacíos de poder metropolitano? Madrid: Instituto Juan Herrera. Recuperado de http://habitat.aq.upm. es/boletin/n21/aafau.html

Fernández B. (2000). Le Corbusier: una arquitectura para el hombre. Espacio, Tiempo y Forma, 7(13), 567-577.

Foo, K., Martin, D., Wool, C., y Polsky, C. (2014). Reprint of the production of urban vacant land: relational placemaking, Boston, MA neighborhoods. $\mathrm{Ci}$ ties, 35, 156-163. doi: 10.1016/j.cities.2013.12.006

Foster, J. (2014). Hiding in plain view: vacancy and prospect in Paris' Petite Ceinture. Cities, 40, part B, 124-132. doi: 10.1016/j.cities.2013.12.006

Frago, L., y Martínez, S. (2016). Las utopías urbanas del siglo XIX, herencias y carencias: la carencia social frente a la herencia técnica. En XIV Coloquio Internacional de Geocrítica: las Utopías y la Construcción de la Sociedad del Futuro. Universidad de Barcelona.

Frediani, J. (2014). Tierra vacante y desarrollo urbano en ciudades medias. Estrategias para su recuperación e integración territorial en el Gran La Plata, Argentina. Universitat Politécnica de Catalunya, VI Seminario Internacional de Investigación en Urbanismo, Barcelona-Bogotá. Recuperado de http:// upcommons.upc.edu/revistes/bitstream/2099/15624/1/010_BGT_Frediani_Julieta.pdf

Fuentes Flores, C. M. (2009). La estructura espacial urbana y accesibilidad diferenciada a centros de empleo en Ciudad Juárez, Chihuahua. región y sociedad, 21(44), 117-144. doi: 10.22198/rys.2009.44.a458

Garza, G. (1997). Normatividad urbanística virtual en la Ciudad de México. Economía, Sociedad y Territorio, 1(1), 41-110.

Godoy, S. (2007). Posibilidades de aprovechamiento de los vacíos urbanos para lograr ambientes saludables en localidades del área metropolitana del Gran Resistencia. Caso Barranqueras. Universidad del Grupo. VI Bienal del Coloquio de Transformaciones Territoriales. Santa Fe, Argentina. Recuperado de http://www.augm-cadr.org.ar/archivos/6to-coloquio/pdf/02 07.pdf 
Hilberseimer, L. (1999). La arquitectura de la gran ciudad. Barcelona: Editorial Gustavo Gili.

Instituto Nacional de Estadística y Geografía (INEGI). (2015a). Encuesta Intercensal. Ciudad de México: INEGI. Recuperado de http://www.cuentame. inegi.org.mx/monografias/informacion/tlax/territorio/div_municipal.aspx?tema=me\&e $=29$

Instituto Nacional de Estadística y Geografía (INEGI). (2015b). Datos geográficos vectoriales en formato shapefile con cobertura nacional y estatal. Ciudad de México: INEGI. Recuperado de http://www.beta.inegi.org.mx/datos/

Kremer, P., Hamstead, Z., y Mcphearson, T. (2013). Social-ecological assessment of vacant lots in New York City. Landscape and Urban Planning, 120, 218-233. doi: 10.1016/j.landurbplan.2013.05.003

Le Corbusier. (1989). Principios de urbanismo. La carta de Atenas. Barcelona: Ariel.

Lombard, M. (2015). Lugarización y la construcción de asentamientos informales en México. Revista INVI, 30(83), 101-129.

López Navarrete, J. A., y Peña Medina, S. (2017). La segregación socioespacial en Ciudad Juárez, Chihuahua, 1990-2010. región y sociedad, 29(68), 115152. doi: $10.22198 /$ rys.2017.68.a210

Mallach, A., y Brachman, L. (2013). Regenerating America's Legacy Cities. Cambridge, Massachusetts: Lincoln Institute-Land Policy. Recuperado de https://www.lincolninst.edu/pubs/dl/2215_1582_Regenerating_Americas_Legacy_Cities.pdf

Mattos, C. de, Fuentes, L., y Link, F. (2014). Tendencias recientes del crecimiento metropolitano en Santiago de Chile. ¿Hacia una nueva geografía urbana? Revista INVI, 29(81), 193-219.

Mignaqui, I., y Arias, S. (2008). Política fundiaria y desarrollo urbano: oportunidades y amenazas para la tierra vacante en Buenos Aires. II Seminario Políticas Urbanas, Gestión Territorial y Ambiental para el Desarrollo Local. FAU-UNNE, Buenos Aires, Argentina.

Montiel Álvarez, T. (2015). Ebenezer Howard y la ciudad jardín. ArtyHum, Revista Digital de Artes y Humanidades, 9, 118-123.

Nassauer, J., y Raskin, J. (2014). Urban vacancy and land use legacies: a frontier for urban ecological research, design, and planning. Landscape and Urban Planning, 125, 245-253. doi: 10.1016/j.landurbplan.2013.10.008

Pagano, M. , y Bowmann, A. (2000). Vacant land in cities: an urban resource. Washington, D. C.: The Brookings Institution, Survey Series, 1-9. Recuperado de http: / / www.brookings.edu/ / media/research/files/reports/2001/1/01-vacant-land-pagano/paganofinal.pdf

Pearsall, H., Lucas, S., y Lenhardt, J. (2014). The contested nature of vacant land in Philadelphia and approaches for resolving competing objectives for redevelopment. Cities, 40, 163-174. doi: 10.1016/j.cities.2013.04.008

Pérez-Campuzano, E. (2010). Segregación socioespacial en ciudades turísticas. El caso de Puerto Vallarta, México. región y sociedad, 22(49), 142-176. doi: 10.22198/rys.2010.49.a425 
Pradilla Cobos, E. (2014). La ciudad capitalista en el patrón neoliberal de acumulación en América Latina. Cadernos Metrópole, 16(31), 37-60. Recuperado de https://www.scielo.br/pdf/cm/v16n31/2236-9996-cm-16-31-0037. pdf

Precedo, A., y Míguez, A. (2014). Las ciudades medias en la globalización. Madrid: Editorial Síntesis.

Prévôt Schapira, M.-F. (2000). Segregación, fragmentación, secesión. Hacia una nueva geografía social en la aglomeración de Buenos Aires. Economía, Sociedad y Territorio, 2(7), 405-431.

Tejeda Parra, G., y Lara Enríquez, B. E. (2018). Déficit de vivienda y satisfacción residencial. Un comparativo entre la frontera norte de México y el país, 2014. región y sociedad, 30(71), 1-36. doi: 10.22198/rys.2018.71.a811

Tello-Campos, C. A. , y Aguilar-Martínez, A. G. (2013). Regeneración y calidad de vida urbana en el centro antiguo de las ciudades de Montreal y México: una comparación. Economía, Sociedad y Territorio, 13(41), 121-149.

The 110th American Assembly. (2011). Reinventing America's legacy cities. Strategies for cities losing population. The 110th American Assembly. Detroit, Michigan: Westin Book Cadillac. Recuperado de http://www.achp.gov/docs/ Reinventing_Americas_Legacy_Cities_0.pdf

Ulloa, R. (2008) Teoría y praxis en Walter Gropius. Revista de Arquitectura, 10, 69-74. Recuperado de https://www.redalyc.org/articulo. oa?id $=1251 / 125112541010$

Urrieta, S. (2009). El reino de lo urbano y la muerte de la ciudad. Andamios, 6(12), 157-187.

Velasco Delgado, E., y Bustamante López, C. (2006). La Ciudad de Tlaxcala y su zona conurbada. México: Universidad Autónoma de Tlaxcala y CIISDER.

Whitaker, S., y Fitzpatrick, T. (2013). Deconstructing distressed-property spillovers: the effects of vacant, tax-delinquent, and foreclosed properties in housing submarkets. Journal of Housing Economics, 22(2), 79-91. doi: 10.1016/j.jhe.2013.04.001

Yanes Díaz, G. (2010). Modelo de planeación integral en la zona metropolitana Puebla-Tlaxcala. México: El Colegio de Tlaxcala. 